\title{
Identification of BLyS (B Lymphocyte Stimulator), a Non-Myelin-Associated Protein, as a Functional Ligand for Nogo-66 Receptor
}

\author{
Lei Zhang, ${ }^{1,2}$ Sushuang Zheng, ${ }^{1}$ Haitao $\mathrm{Wu},{ }^{3}$ Yan $\mathrm{Wu},{ }^{3}$ Shuhong Liu, ${ }^{3}$ Ming Fan, ${ }^{3}$ and Jian Zhang ${ }^{1}$ \\ ${ }^{1}$ Laboratory of Molecular and Developmental Biology, Institute of Genetics and Developmental Biology, the Chinese Academy of Sciences, Beijing 100101, \\ China, ${ }^{2}$ Graduate School of the Chinese Academy of Sciences, Beijing 100039, China, and ${ }^{3}$ Department of Neurophysiology, Institute of Basic Medical \\ Sciences, Beijing 100850, China
}

B lymphocyte stimulator (BLyS), a tumor necrosis factor family protein essential for B cell development, was previously shown to be expressed at an elevated level in the CNS of multiple sclerosis patients. Although it may be involved in CNS diseases, its exact functions in CNS remain unknown. We hypothesize that BLyS may be a negative regulator for neuronal functions. Here Nogo-66 receptor (NgR) is identified as a high affinity receptor for BLyS, which inhibits dorsal root ganglion outgrowth in culture. The inhibition by BLyS can be reversed by a truncated NgR or by removal of glycosylphosphatidylinositol-linked proteins from neurons. More importantly, the inhibitory effect by BLyS is significantly diminished for neurons isolated from $\mathrm{NgR}^{-1-}$ mice. Furthermore, expressions of BLyS and NgR are also found to be associated with astrocytes and macrophages/microglial cells at spinal cord injury sites. Thus, BLyS can function independently of myelin-associated inhibitors and likely serves as a redundant NgR ligand that negatively influences axonal outgrowth in CNS.

\section{Introduction}

Mammalian CNS axons have limited capacity for axonal regeneration after injury. One of the major obstacles is a nonpermissive environment of the adult CNS, which includes oligodendrocytes and astrocytes among others. Myelin-derived proteins, such as Nogo, myelin-associated glycoprotein (MAG), and oligodendrocyte myelin glycoprotein (Omgp), are key inhibitors to prevent CNS axons from regeneration (He and Koprivica, 2004). In the last few years, the three inhibitors were all shown to bind to a common glycosylphosphatidylinositol (GPI)-anchored protein Nogo-66 receptor (NgR) (McGee and Strittmatter, 2003). Blockage of signaling through $\mathrm{NgR}$ was considered to be essential for reversing actions of these inhibitors on CNS axonal regeneration (McKerracher and David, 2004). A number of studies indeed showed that neutralization of these inhibitors by antibodies or soluble receptor peptides could improve axon regeneration and even some functional recovery in physiological tests ( $\mathrm{Li}$ and Strittmatter, 2003; Atalay et al., 2007). In addition, some regeneration was detected in the raphespinal and rubrospinal fibers in a mouse strain lacking $\mathrm{NgR}$ (Kim et al., 2004). However, deletion of $\mathrm{NgR}$ did not show benefits for corticospinal tract regeneration

Received 0ct. 18, 2008; revised March 28, 2009; accepted April 13, 2009.

This study was supported by the Natural Science Foundation of China (Grant 30425013) and the Ministry of Science and Technology of China (Grants 2005CB522502, 2006CB504100, and 2007CB947201). We thank Drs. Peihua Lu, Minghong Yan, Moses Chao, Pascal Schneider, Douglas Golenbock, Binhai Zheng, and Marc TessierLavigne for sharing reagents or animals, and Drs. Jiajia Liu, Cheng He, and members of the Zhang laboratory for helpful discussions during the study. L.Z. thanks Xiaoguang Wei for support.

Correspondence should be addressed to Dr. Jian Zhang, Laboratory of Molecular and Developmental Biology, Institute of Genetics and Developmental Biology, the Chinese Academy of Sciences, Beijing 100101, China. E-mail: jianzhang84@genetics.ac.cn.

DOI:10.1523/JNEUROSCI.5040-08.2009

Copyright $\odot 2009$ Society for Neuroscience $\quad$ 0270-6474/09/296348-05\$15.00/0
(Kim et al., 2004; Zheng et al., 2005). A more recent investigation also indicated that $\mathrm{NgR}$ was only required for acute growth cone collapse but not for chronic inhibition by myelin-associated inhibitors (Chivatakarn et al., 2007).

However, astrocytes were found to be activated in response to all forms of CNS injury or diseases (Higuchi et al., 2002). The reactive astrocytes exhibited altered gene expression, hypertrophy, and proliferation (Bush et al., 1999). Both beneficial and detrimental effects have been attributed to the reactive astrocytes after CNS injury, but underlying mechanisms are still not well understood (Bush et al., 1999). Few molecules from astrocytes have been implicated in the neuron regeneration process (Deneen et al., 2006). Recently, astrocytes in multiple sclerosis (MS) patients were shown to have upregulated expression of B lymphocyte stimulator (BLyS), a tumor necrosis factor family member (also called BAFF, TALL-1, CD253 antigen), which is indispensable for B cell development (Krumbholz et al., 2005). However, possible functions of B lymphocyte stimulator (BLyS) in MS have not been explored. The observation that BLyS expresses in MS neural tissues prompted us to speculate that it may have direct roles at sites of CNS lesions. In this study, we used an expression cloning approach to search for BLyS receptors in CNS and identified NgR as a binding receptor for BLyS. We show that BLyS can inhibit neurite outgrowth, and such inhibition is dependent on functional $\mathrm{NgR}$. Our results demonstrate that a molecule critical for homeostasis of immune system also plays an important role in CNS neuron regeneration. Possible implications of this interaction in development of autoimmune diseases such as MS are also discussed.

\section{Materials and Methods}

Plasmids. Human $\mathrm{NgR}, \mathrm{NgRH1}, \mathrm{NgRH}$, and Lingol full-length cDNAs were amplified from a human fetal brain cDNA library. Human decay- 


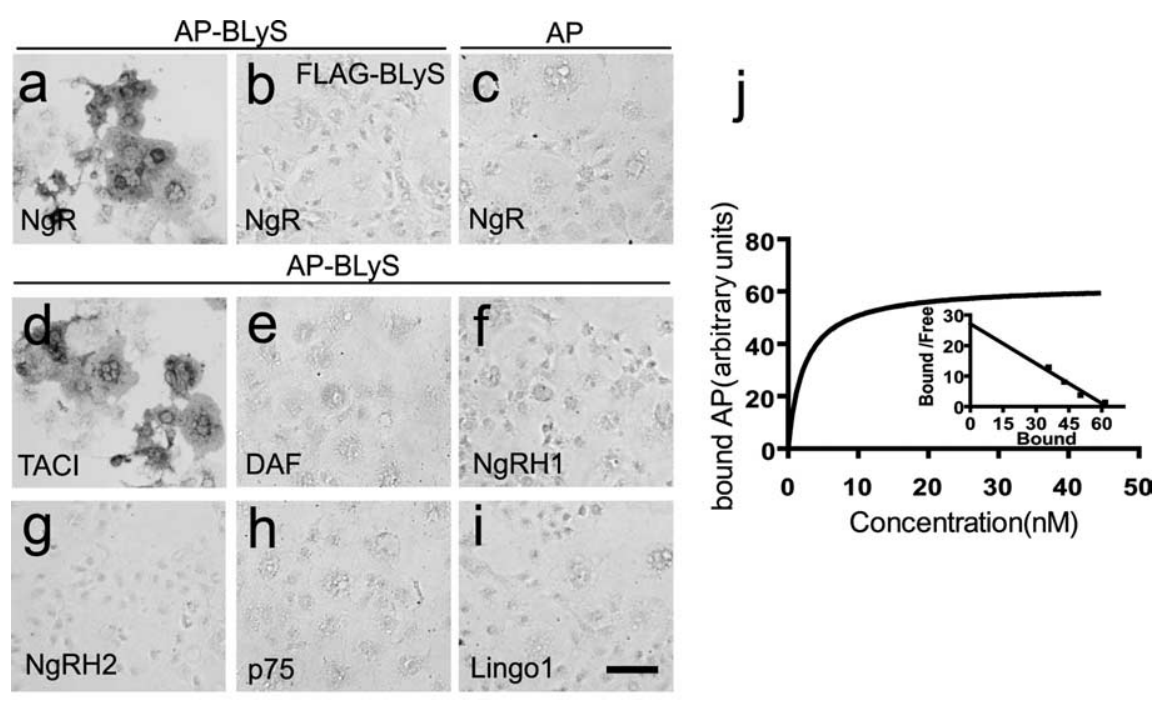

$\mathrm{k}$

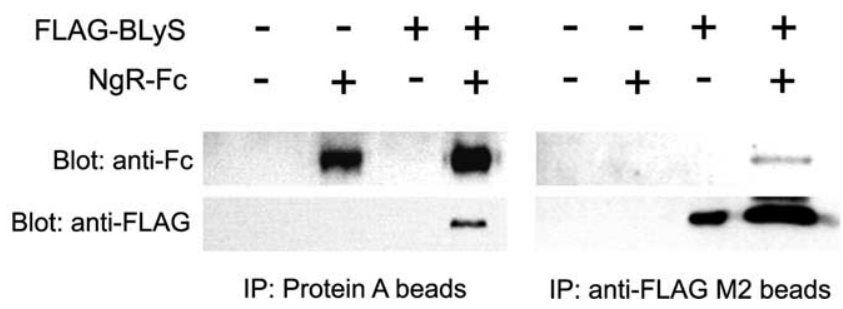

Figure 1. BLyS interacts with NgR. $\boldsymbol{a}-\boldsymbol{c}$, COS-7 cells transfected with human NgR cDNA are incubated with AP-BLyS (a), with AP-BLyS but precincubated with FLAG-BLyS (b), or with AP (c). Bound AP is visualized using NBT/BCIP as a substrate. $\boldsymbol{d}-\boldsymbol{i}, \mathrm{IACI}(\boldsymbol{d})$, $\operatorname{DAF}(\boldsymbol{e}), \operatorname{NgRH} 1$ and $\operatorname{NgRH2}(\boldsymbol{f}, \boldsymbol{g})$, and $p 75$ and Lingo $1(\boldsymbol{h}, \boldsymbol{i})$, respectively, are transfected into COS-7 cells. The resulting cells are incubated with AP-BLyS and stained for AP activity visualization. TACl is a known receptor for BLyS. DAF is a GPI-linked protein. $\mathrm{NgRH} 1$ and $\mathrm{NgRH} 2$ are NgR homolog proteins. p75 and Lingo1 are coreceptors for NgR. Scale bar, $100 \mu \mathrm{m}$. $\boldsymbol{j}$, Quantification of AP-BLyS binding to NgR-expressing COS-7 cells. Binding affinity $\left(K_{\mathrm{d}}\right)$ is calculated as $4.60 \pm 1.15 \mathrm{~nm}$ using the binding saturation curve. Inset is the Scatchard plot. $\boldsymbol{k}$, Interaction of soluble $\mathrm{NgR}$ and BLyS in solution. Purified human $\mathrm{NgR-Fc}$ is incubated with human FLAG-BLyS in TBS solution. The mixture was immunoprecipitated with protein A agarose or anti-FLAG M2 beads, respectively. Antibody against FLAG was used to detect FLAG-BLyS. Antibody against human Fc was used to detect NgR-Fc.

accelerating factor $(D A F)$ cDNA was cloned into pRK5-tkneo vector (McCallum et al., 2006). pFLAG-AP-BLyS-CMV1 and transmembrane activator CAML-interactor (TACI) plasmids were both obtained from Dr. Minghong Yan (Genentech, South San Francisco, CA) (Yan et al., 2000). pBluescriptKS-p75 plasmid containing human $p 75$ full-length cDNA was a gift from Dr. Moses Chao (Cornell University, New York, NY). p75 full-length fragment was cloned into pRK5-tkneo vector. FLAG-AP-Nogo66 is a fusion protein of human Nogo-66 (aa 1055-1120 in NogoA) and alkaline phosphatase (AP) at $\mathrm{NH}_{2}$ terminus and was produced from $p F L A G-A P-N o g o 66-C M V 1$ plasmid. PCR-3-FLAG-BAFF plasmid, which contains sequence encoding the extracellular domain of human BLyS (aa 137-285) fused with FLAG tag at N-terminal plasmid, was a gift from Dr. Pascal Schneider (University of Lausanne, Lausanne, Switzerland).

Protein expression and purification. All of the proteins were transiently expressed in HEK 293T cells using a calcium phosphate transfection method. Conditional medium was concentrated using Centricon tubes Plus-20 (Millipore). Human NgR (aa 1-447) and Fc fusion protein was purified by immobilized protein A agarose (RepliGen). FLAG-BLyS and FLAG-AP-Nogo66 were purified using anti-FLAG M2 affinity gel (Sigma). Protein concentrations were determined by SDS-PAGE analysis of serial dilutions of the preparations in parallel with serial dilutions of a bovine serum albumin standard. AP activities of AP fusion proteins were calculated using standard curves of EIA grade alkaline phosphatase.

Expression cloning. The expression cloning procedure was adapted from previous protocols (Liu et al., 2002). Briefly, COS-7 cells were trans- fected with cDNAs using Polyfect (QIAGEN). Thirty-six to $48 \mathrm{~h}$ after transfection, cells were washed with HBHA (20 mM HEPES, pH7.0, $0.1 \% \mathrm{NaN}_{3}, 0.5 \mathrm{mg} / \mathrm{ml} \mathrm{BSA}$ ) and blocked in DMEM, pH7.0, 10\% bovine serum, and $50 \mathrm{~mm}$ HEPES. AP-BLyS protein was then added and further incubated for $2 \mathrm{~h}$ at $23^{\circ} \mathrm{C}$. After incubation, cells were washed with precooled HBHA for 6 times, 7 min per wash, before fixation with $1.8 \%$ formaldehyde in HBS (20 mM HEPES, $\mathrm{pH} 7.0,150 \mathrm{~mm} \mathrm{NaCl}$ ) for $10 \mathrm{~min}$ at room temperature. After washing with HBS several times, endogenous AP was inactivated by heating at $65^{\circ} \mathrm{C}$ for $2 \mathrm{~h}$. Cells were then rinsed with AP buffer (100 mm Tris-HCl, pH9.5, $100 \mathrm{~mm} \mathrm{NaCl}$, $50 \mathrm{mM} \mathrm{MgCl}_{2}$ ) and incubated in fresh AP buffer for $10 \mathrm{~min}$. Bound AP fusion proteins were visualized by adding nitroblue tetrazolium $/ 5$ bromo-4-chloro-3-indolyl phosphate toluidinium (NBT/BCIP).

In competition experiments, COS-7 cells were incubated with NgR-Fc or FLAG-BLyS for $1 \mathrm{~h}$ before recombinant AP proteins were added. For qualification of BLyS and NgR binding, NgR-expressing COS-7 cells were lysed in $20 \mathrm{~mm}$ Tris, pH8.0, $0.1 \%$ Triton X-100 after incubation with AP-BLyS and rinse by HBAH. The cell lysates were incubated at $65^{\circ} \mathrm{C}$ for $1 \mathrm{~h}$ and spun at $10,000 \times g$ for $10 \mathrm{~min}$. The amount of bound AP was revealed by $p$-nitrophenyl phosphate disodium (Sigma) and measured at OD $405 \mathrm{~nm}$.

Immunoprecipitation. For BLyS and NgR interaction experiments, purified BLyS or NgR proteins $(4-5 \mu \mathrm{g}$ each) were mixed in $1.5 \mathrm{ml}$ of TBS (10 mm Tris, pH 7.5, $150 \mathrm{~mm} \mathrm{NaCl}$ ) and $0.1 \%$ Tween 20 and incubated for $1 \mathrm{~h}$ at $26-28^{\circ} \mathrm{C}$. The mixture was incubated at $4^{\circ} \mathrm{C}$ for $1 \mathrm{~h}$ with either protein A agarose or anti-FLAG M2 gel. The beads were washed five times with PBS, boiled in $2 \times$ loading buffer, and then resolved on a $10 \%$ SDS polyacrylamide gel. Samples were analyzed by Western blotting. FLAGAP-BLyS or FLAG-BLyS was detected with an anti-FLAG antibody. NgR-Fc was detected with anti-human IgG-HRP.

Primary cell culture, neurite outgrowth, and growth cone collapse assays. $\mathrm{NgR}$ mutant mice in a C57BL/6 background were generously provided by Drs. Marc Tessier-Lavigne (Genentech) and Binhai Zheng (University of California, San Diego, La Jolla, CA). Chicken embryonic day 12 (E12) dorsal root ganglia (DRGs), mouse DRGs, or E17 rat cortical neurons were dissected in HBSS buffer (Hyclone). For neurite outgrowth assay, glass coverslips in 24-well plates were coated by poly-L-lysine (Sigma). One microgram of FLAG-AP-Nogo66 or 200 ng of BLyS (Peprotech) in PBS was spotted on the coverslips and air dried in a tissue culture hood. DRGs were trypsinized and titrated in DMEM containing $10 \%$ fetal bovine serum medium (Hyclone). Three hours after seeding on the plate, one-half of the medium was replaced with fresh Neurobasal complete medium supplemented with $\mathrm{B} 27$ and $30 \mathrm{ng} / \mathrm{ml}$ nerve growth factor (NGF) (Invitrogen). For some experiments, $100 \mathrm{ng}$ of NgR-Fc mixed with $1 \mu \mathrm{g}$ of Nogo-66 or $200 \mathrm{ng}$ of BLyS was spotted on the coverslips. For PI-PLC treatment experiments, $1 \mathrm{U} / \mathrm{ml}$ PI-PLC (Sigma) was immediately added into the medium after replacing one-half of the neuron culture medium. For postnatal day 9 (P9) mice DRG isolation, NgR null mice and their wild-type littermate mice were used (Zheng et al., 2005). For ROCK inhibition experiments, dissociated neurons were treated with 15 $\mu \mathrm{M}$ Y-27632 (Sigma) or PBS during the entire culture period. After culturing for 14-18 h, neurons were rinsed with HBSS twice and fixed with $4 \%$ paraformaldehyde containing $25 \%$ sucrose for $2 \mathrm{~h}$ at room temperature. The cells were blocked in PBS, pH 7.4 containing $0.1 \%$ gelatin, $1 \%$ 

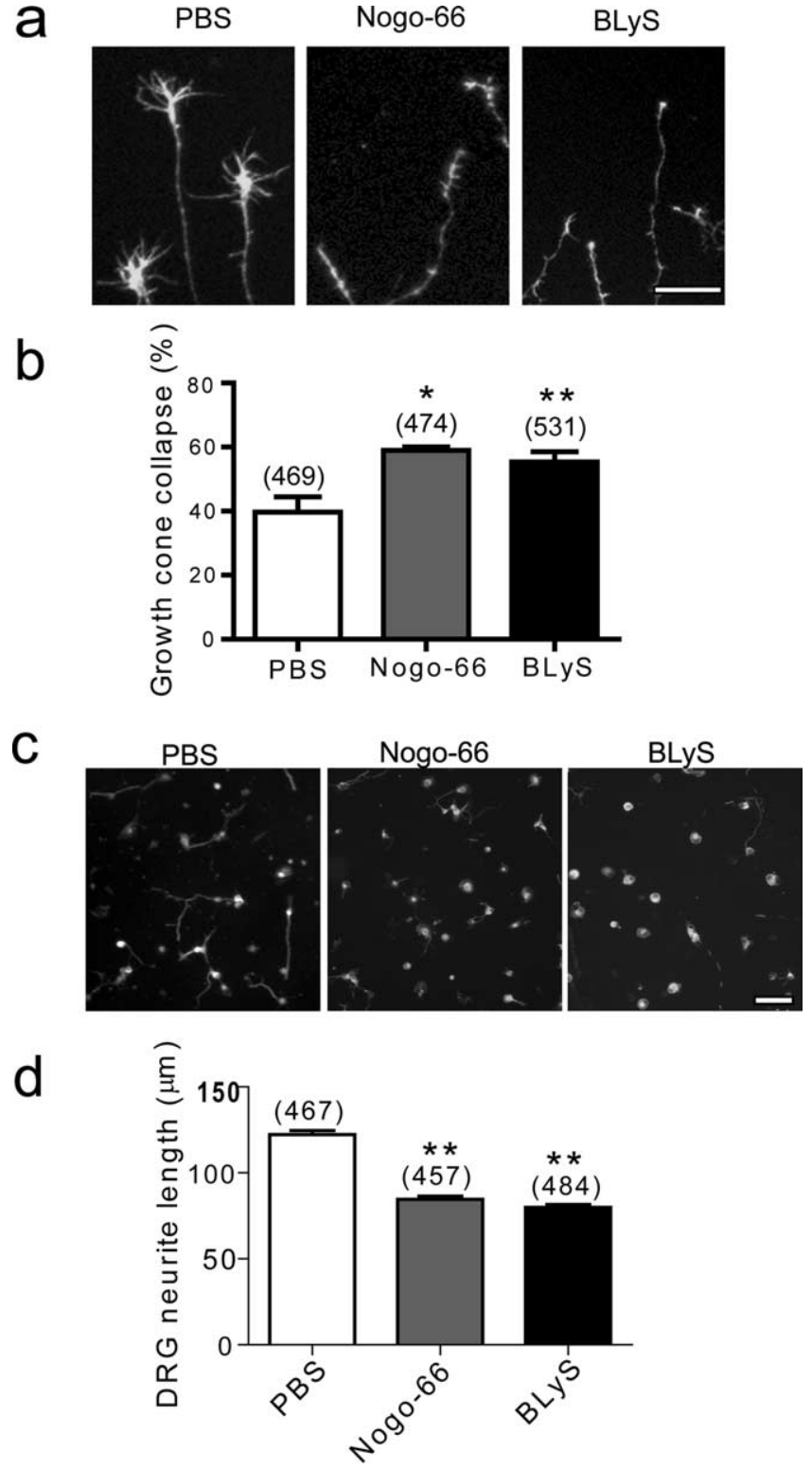

Figure 2. BLyS is an inhibitor for chicken DRG growth. $\boldsymbol{a}$, Chicken E12 DRG explants were exposed to $20 \mathrm{~nm}$ human Nogo-66 or $16 \mathrm{~nm}$ BLyS for $1 \mathrm{~h}$ before fixation and stained with Phalloidin, Alexa Fluor $488 \mathrm{~nm}$. Results were analyzed from three independently repeated experiments using Student's one-tailed $t$ test. Scale bar, $50 \mu \mathrm{m}$. $\boldsymbol{b}$, The growth cones' collapse value was increased in the presence of Nogo-66 or BLyS compared with untreated control, as indicated by asterisks $\left({ }^{*} p<0.04,{ }^{* *} p<0.009\right.$ ). c, Chicken E12 DRGs were isolated and cultured on immobilized substrates. Sixteen hours after culture, DRGs were fixed and stained with monoclonal antibody Tuj 1 against class III $\beta$-tubulin. Scale bar, $100 \mu \mathrm{m}$. $\boldsymbol{d}$, Quantification of E12 chick DRG neurite length inhibition shown in $c$ with Student's two-tailed $t$ test ${ }^{* *} p<$ $0.0001)$. The number of neurites counted for each treatment is indicated in parentheses. The means $\pm S E M$ are presented from four experiments.

BSA, and $0.02 \% \mathrm{NaN}_{3}$ for $1 \mathrm{~h}$ at room temperature. After incubation with monoclonal antibody Tuj 1 against class III $\beta$-tubulin (Millipore) for $50 \mathrm{~min}$ at $26-28^{\circ} \mathrm{C}$, cells were washed with PBS three times, for $8 \mathrm{~min}$ each. Then cells were incubated with a secondary antibody against mouse conjugated with rhodamine (ZSGB-Bio), followed by washing with PBS at least 4 times, for 8 min each. After mounting with PBS, 80\% glycerol, and $4 \%$ propyl gallate (Sigma), the DRG neurites were observed under a Nikon ECLIPSE TE2000-U fluorescence microscope. Photographs were captured using a mounted Coolsnap ES CCD camera (Roper Scientific). Only well separated neurites longer than one cell body diameter were counted. Neurite length was measured from the central cell body to the end of neurite (Lagenaur and Lemmon, 1987) using RS image software (Roper Scientific).

For growth cone collapse assay, glass coverslips were sequentially coated with poly-L-lysine and laminin (Sigma). Dissociated E12 chick DRG explants were cultured in DMEM/F12 medium containing 10\% fetal bovine serum, $1 \%$ penicillin/streptomycin, $1 \%$ glutamine, and 50 $\mathrm{ng} / \mathrm{ml}$ NGF. The explants were treated with $20 \mathrm{~nm}$ Nogo-66 or $16 \mathrm{~nm}$ $\mathrm{BLyS}$ at $37^{\circ} \mathrm{C}$ for $1 \mathrm{~h}$. The explants were then fixed with $4 \%$ paraformaldehyde with $20 \%$ sucrose. Alexa Fluor 488 phalloidin (Cambrex) was used to visualize the growth cones. Only well separated growth cones were scored. The tips of axons were scored as having a growth cone if they exhibited either a lamellipodium or $\geq 3$ filopodia (Luo et al., 1993).

Each quantification experiment was repeated at least three times. Photographs were taken randomly but not repeatedly. Samples were counted in a double-blind manner in each quantification experiment. Data were analyzed by Student's $t$ test using GraphPad Prism 5.0 software. All error bars represent SEM.

\section{Results}

\section{Identification of BLyS as a new ligand for $\mathrm{NgR}$}

During B-cell development, BLyS interacts with several known receptors, such as BLyS receptor 3 (BR3), TACI, and B-cell maturation antigen (BCMA) (Cancro, 2004). BLyS was previously shown to be upregulated in the CNS of MS patients (Krumbholz et al., 2005); thus, it is possible that the known BLyS receptors may also be expressed in nervous system to mediate BLyS functions in CNS. To this end, we examined expressions of TACI and $B C M A$ in chicken DRGs by reverse transcription-PCR. BR3 was not identified by BLASTing chicken genomic sequences. TACI and $B C M A$ were found expressed at a very low level during early neurogenesis (supplemental Fig. 1, available at www.jneurosci.org as supplemental material). We reasoned that other BLyS binding partners might exist in neural tissues. Indeed, we showed that a soluble alkaline phosphatase (AP) and BLyS fusion protein (AP-BLyS) bound to chicken DRGs in culture with high affinity (data not shown), suggesting that a potential new binding factor other than TACI or BMCA is expressed on the surface of DRGs. We sought to identify the BLyS binding partners using an expression cloning strategy based on the binding of soluble AP-BLyS. AP-BLyS was used to screen pools of a human fetal brain cDNA expression library transfected into COS-7 cells. One pool with very high AP binding activity was identified. A single cDNA clone was recovered through sib selections from this pool. Retransfection of this cDNA into COS-7 cells resulted in high-affinity binding sites presented on the cell surface (Fig. 1a). Sequence information of the clone revealed that the cDNA encoded the open reading frame of $\mathrm{NgR}$. This suggests that NgR may function as the binding site that we previously discovered, although existence of additional BLyS binding sites cannot be excluded. In addition, FLAG-BLyS blocked NgR and AP-BLyS interaction, indicating that the binding is specific (Fig. 1b). AP-BLyS showed no binding to COS-7 cells expressing NgR homolog proteins, NgRH1 and NgRH2 (Fig. 1f,g). Nor did AP-BLyS bind to COS-7 cells expressing p75 or Lingo1, which are known NgR coreceptors (Fig. $1 h, i)$. The binding affinity $\left(K_{\mathrm{d}}\right)$ between AP-BLys and NgR was calculated to be $4.60 \pm 1.15 \mathrm{~nm}$ (Fig. $1 j$ ). We next did coimmunoprecipitation experiments by incubating purified FLAG-BLyS and $\mathrm{NgR}-\mathrm{Fc}$, which is a fusion protein of the extracellular domain of $\mathrm{NgR}$ and Fc. FLAG-BLyS and NgR-Fc were pulled down by protein A beads or anti-FLAG beads, respectively, suggesting direct interaction between soluble BLyS and NgR (Fig. 1k). Together, these results show that the soluble form of BLyS can specifically bind to $\mathrm{NgR}$ in vitro. 

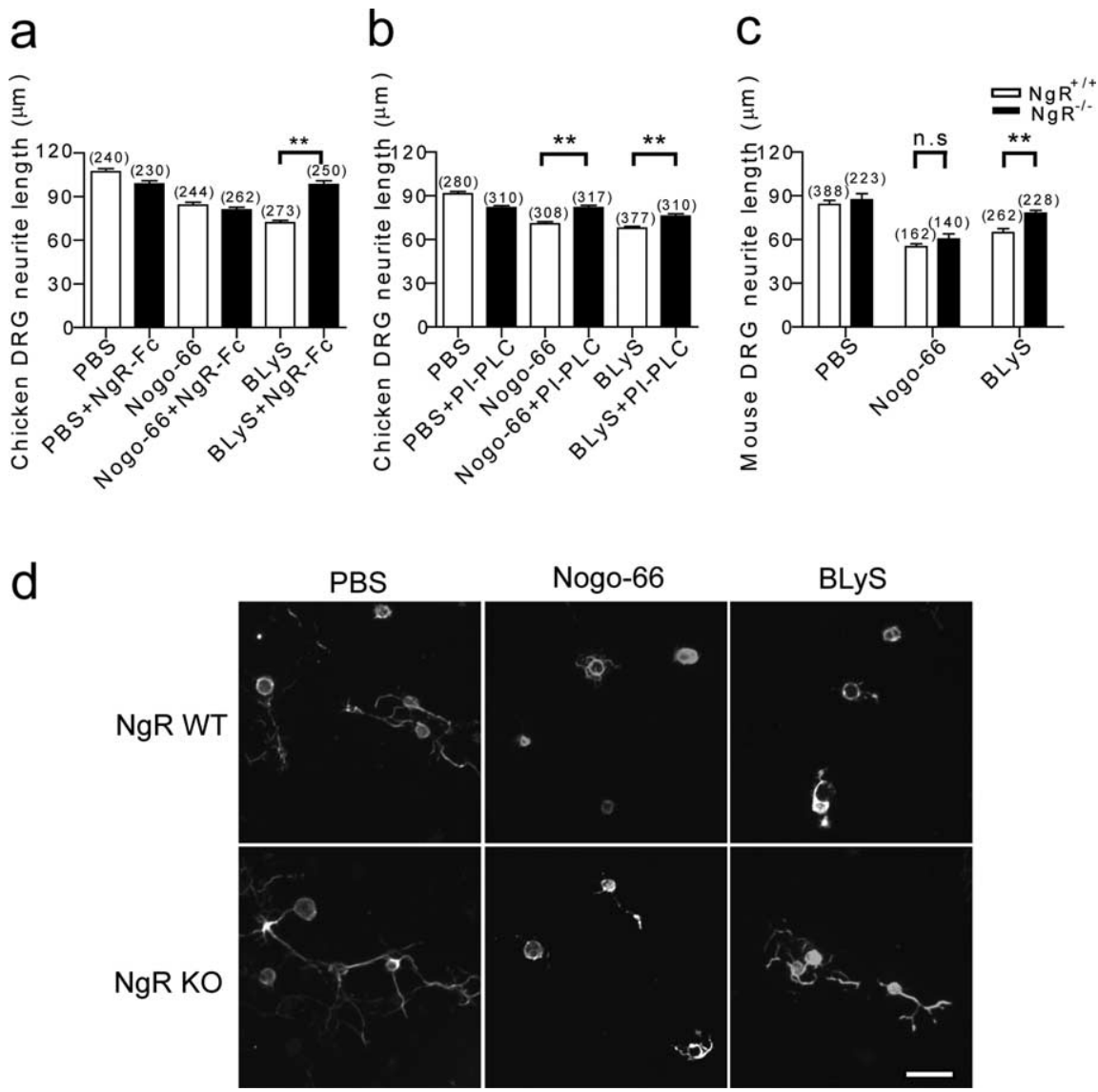

Figure 3. $\mathrm{NgR}$ is indispensable for BLyS inhibition of neurite outgrowth. $\boldsymbol{a}$, Quantification of $\mathrm{E} 12$ chick DRG neurite length on different immobilized substrates. In the presence of NgR-Fc, inhibition of neurite length by BLyS is reduced. ${ }^{* *} p<0.001$, by Student's two-tailed $t$ test with $95 \%$ confidence interval. $\boldsymbol{b}$, Quantification of DRG neurite length on inhibitory substrates in the presence of PI-PLC. ${ }^{*} p<0.04$, by Student's two-tailed $t$ test with $95 \%$ confidence interval. c, Quantification of DRG neurite length of wild-type $\left(\mathrm{NgR}^{+/+}\right)$and $\mathrm{NgR}$-deficient $\left(\mathrm{NgR}^{-/-}\right)$neurons on inhibitory substrates as indicated in $\boldsymbol{d} .{ }^{* *} p<0.001$, by Student's two-tailed $t$ test with $95 \%$ confidence interval. $\boldsymbol{d}$, P9 DRG neurons from wild-type or NgR-deficient mice were dissociated and cultured on control substrates or substrates containing recombinant Nogo-66 or BLyS. DRGs were fixed and stained using monoclonal antibody Tuj 1 against class III $\beta$-tubulin. Scale bar, $100 \mu \mathrm{m}$. Neurite length analysis in $\boldsymbol{a}, \boldsymbol{b}$, and $\boldsymbol{c}$ was performed blindly. The number of neurites counted (means \pm SEM) for each treatment is indicated in parentheses.

\section{BLyS collapses DRG axons and inhibits neurite outgrowth}

Since NgR functions as a receptor to mediate axon outgrowth inhibition by NogoA, MAG, and Omgp (McKerracher and David, 2004), we reasoned that BLyS might have similar effects on axon outgrowth. To explore this possibility, we isolated chicken E12 DRG neurons and used them for BLyS inhibition assays. When BLyS was added to DRG explant culture medium, it collapsed growth cones as shown with Phalloidin staining (Fig. $2 a, b)$. To ensure obtaining confident results, we repeated the experiments three times and analyzed the data in a double-blind manner (all inhibition analyses in this study were performed similarly).

In a separate assay, we measured the possible influence of BLyS on neurite outgrowth. As in the axon collapse assay, BLyS strongly inhibited neurite outgrowth of E12 chicken DRGs and E17 rat cortical neurons (Fig. $2 c, d$; supplemental Fig. 2a,b, available at www.jneurosci.org as supplemental material). The inhibitory responses induced by BLyS were similar to that caused by treatment of the same neurons with an AP fusion protein containing the 66-aa extracellular domain of NogoA (He et al., 2003). These results suggest that BLyS, like Nogo-66, OMgp, and MAG, is a potent neurite outgrowth inhibitor.
Inhibition of neuron outgrowth by BLyS is dependent on $\mathrm{NgR}$ and RhoA activation

If the inhibition of neuronal outgrowth by BLyS is through $\mathrm{NgR}$, then interference of the interaction between BLyS and $\mathrm{NgR}$ should prevent such inhibition. To test this possibility, we first confirmed that in the presence of NgR-Fc, binding ability of APBLyS to COS-7 cells expressing NgR was significantly decreased, suggesting that the BLyS binding to $\mathrm{NgR}$ was specific (supplemental Fig. 3, available at www.jneurosci.org as supplemental material). When NgR-Fc and BLyS were added together to chicken E12 DRG culture, the neurite outgrowth was significantly better than that of BLyS-treated culture (Fig. 3a). Since NgR is a GPIanchored membrane protein, it is conceivable that removal of GPI proteins from neurons should block $\mathrm{NgR}$ signaling and its mediated inhibition. Indeed, addition of phosphatidylinositol-specific phospholipase C (PI-PLC), which can clip all GPI-anchored proteins from cell surface, to chicken E12.5 DRG culture significantly restored the neurite outgrowth (Fig. 3b). To further test whether $\mathrm{NgR}$ is required for BLyS inhibition, we isolated DRGs from postnatal day 9 mice deficient of NgR (Zheng et al., 2005) and cultured them in the presence of BLyS. Loss of $\mathrm{NgR}$ significantly reversed the neurite outgrowth inhibition by BLyS (Fig. 3c,d). These results indicate that NgR is required for BLyS-induced inhibition in neurite outgrowth.

Previously, NgR was shown to activate small GTPase RhoA in Nogo-66-, MAG-, or Omgp-induced axon collapse or neurite outgrowth (He and Koprivica, 2004). We examined whether modulation of RhoA pathway had any impact on the inhibition caused by BLyS. Y-27632, which is a specific inhibitor for ROCK, a RhoA downstream effector (Fournier et al., 2003), was chosen for the assay. Chicken E12 DRGs were dissociated and plated on different inhibitory substrates. We found that addition of Y-27632 fully restored neurite outgrowth to a level similar to that of untreated control (supplemental Fig. 4a,b, available at www.jneurosci.org as supplemental material). Since BLyS is well known for its functions in immune cells by activating the nuclear factor $\kappa \mathrm{B}(\mathrm{NF}-\kappa \mathrm{B})$ pathway, we also examined whether NgR could mediate ligand-induced NF- $\kappa$ B signaling, which in turn might negatively influence neurite growth. Results from ELAM (Eselectin) luciferase reporter assay in COS-7 cells suggested that BLyS may not activate NF- $\kappa \mathrm{B}$ pathway via $\mathrm{NgR} / \mathrm{p} 75 /$ Lingol receptor complex (supplemental Fig. 5, available at www.jneurosci.org as supplemental material). Together, the results suggest that BLyS can inhibit neurite outgrowth via $\mathrm{NgR}$, and this inhibition is dependent on RhoA activation.

\section{Discussion}

The unfavorable axonal regeneration environment in CNS has been partially attributed to myelin-associated inhibitors. Apart from Nogo, MAG, and Omgp, which bind to NgR, other myelin- 
associated inhibitors including Sema4D, ephrin-B3, and Netrin-1 are also implicated in blocking axonal regeneration (Löw et al., 2008). In this study, BLyS is identified as a new ligand for NgR and inhibits DRG axon outgrowth. Such inhibition is mainly dependent on NgR expressed in the neurons. Our results thus implicate a protein, which was previously shown to be essential in B cell development, as also being critical in neuron regeneration.

We find that expressions of BLyS and NgR are overlapped in the CNS (data not shown), suggesting that the interaction between BLyS and NgR is biologically relevant in vivo. Weak expression of BLyS is found in normal spinal cord, but the expression is markedly upregulated and colocalized with astrocytes and macrophages/microglial cells at the spinal cord injury sites in rats (supplemental Fig. 6, available at www.jneurosci.org as supplemental material). Similarly, not only is NgR expressed in neurons, but it is also associated with astrocytes and macrophages/ microglial cells after spinal cord injury (supplemental Fig. 7, available at www.jneurosci.org as supplemental material), which is consistent with a recent study (David et al., 2008).

What types of cells secrete BLyS detected in CNS? Astrocytes were reported as the main source for BLyS expression in the CNS of MS patients (Krumbholz et al., 2005, 2008). In addition, BLyS was also found to be persistently upregulated in the CNS of mice with relapsing-remitting and chronic-relapsing experimental autoimmune encephalomyelitis (EAE) (Magliozzi et al., 2004). From BLyS expression analysis (supplemental Fig. 6, available at www.jneurosci.org as supplemental material), we speculate that BLyS expression in astrocytes may be enhanced after spinal cord injury. If this is the case, then locally secreted BLyS from astrocytes may directly bind to $\mathrm{NgR}$ on neurons to regulate outgrowth. However, peripheral macrophages that infiltrate into injury sites may also secrete BLyS and upregulate their own NgR expression. Thus, macrophage-derived BLyS may function in an autocrine manner to activate $\mathrm{NgR}$ and indirectly affect neuron regeneration (Novak et al., 2002).

Since BLyS strongly inhibits neurite outgrowth and collapses axons, it may play a detrimental role in CNS lesions as suggested by elevated BLyS expression in MS patients and in a rat spinal cord injury model (supplemental Fig. 6, available at www.jneurosci.org as supplemental material). Our results reinforce the idea that blocking BLyS and NgR interaction may be a necessary measure for successful axonal regeneration. However, it is tempting to speculate that interfering BLyS and NgR interaction may help ameliorate symptoms of MS patients. EAE animal models based on BLyS, NgR, and BR3 conditional knock-out mice can be used to test this hypothesis.

\section{References}

Atalay B, Bavbek M, Cekinmez M, Ozen O, Nacar A, Karabay G, Gulsen S (2007) Antibodies neutralizing Nogo-A increase pan-cadherin expression and motor recovery following spinal cord injury in rats. Spinal Cord 45:780-786.

Bush TG, Puvanachandra N, Horner CH, Polito A, Ostenfeld T, Svendsen CN, Mucke L, Johnson MH, Sofroniew MV (1999) Leukocyte infiltration, neuronal degeneration, and neurite outgrowth after ablation of scarforming, reactive astrocytes in adult transgenic mice. Neuron 23:297-308.

Cancro MP (2004) The BLyS family of ligands and receptors: an archetype for niche-specific homeostatic regulation. Immunol Rev 202:237-249.
Chivatakarn O, Kaneko S, He Z, Tessier-Lavigne M, Giger RJ (2007) The Nogo-66 receptor NgR1 is required only for the acute growth conecollapsing but not the chronic growth-inhibitory actions of myelin inhibitors. J Neurosci 27:7117-7124.

David S, Fry EJ, López-Vales R (2008) Novel roles for Nogo receptor in inflammation and disease. Trends Neurosci 31:221-226.

Deneen B, Ho R, Lukaszewicz A, Hochstim CJ, Gronostajski RM, Anderson DJ (2006) The transcription factor NFIA controls the onset of gliogenesis in the developing spinal cord. Neuron 52:953-968.

Fournier AE, Takizawa BT, Strittmatter SM (2003) Rho kinase inhibition enhances axonal regeneration in the injured CNS. J Neurosci 23:1416-1423.

He XL, Bazan JF, McDermott G, Park JB, Wang K, Tessier-Lavigne M, He Z, Garcia KC (2003) Structure of the Nogo receptor ectodomain: a recognition module implicated in myelin inhibition. Neuron 38:177-185.

He Z, Koprivica V (2004) The Nogo signaling pathway for regeneration block. Annu Rev Neurosci 27:341-368.

Higuchi M, Ishihara T, Zhang B, Hong M, Andreadis A, Trojanowski J, Lee VM (2002) Transgenic mouse model of tauopathies with glial pathology and nervous system degeneration. Neuron 35:433-446.

Kim JE, Liu BP, Park JH, Strittmatter SM (2004) Nogo-66 receptor prevents raphespinal and rubrospinal axon regeneration and limits functional recovery from spinal cord injury. Neuron 44:439-451.

Krumbholz M, Theil D, Derfuss T, Rosenwald A, Schrader F, Monoranu CM, Kalled SL, Hess DM, Serafini B, Aloisi F, Wekerle H, Hohlfeld R, Meinl E (2005) BAFF is produced by astrocytes and up-regulated in multiple sclerosis lesions and primary central nervous system lymphoma. J Exp Med 201:195-200.

Krumbholz M, Faber H, Steinmeyer F, Hoffmann LA, Kümpfel T, Pellkofer H, Derfuss T, Ionescu C, Starck M, Hafner C, Hohlfeld R, Meinl E (2008) Interferon-beta increases BAFF levels in multiple sclerosis: implications for B cell autoimmunity. Brain 131:1455-1463.

Lagenaur C, Lemmon V (1987) An L1-like molecule, the 8D9 antigen, is a potent substrate for neurite extension. Proc Natl Acad Sci USA 84:7753-7757.

Li S, Strittmatter SM (2003) Delayed systemic Nogo-66 receptor antagonist promotes recovery from spinal cord injury. J Neurosci 23:4219-4227.

Liu BP, Fournier A, GrandPré T, Strittmatter SM (2002) Myelin-associated glycoprotein as a functional ligand for the Nogo-66 receptor. Science 297:1190-1193.

Löw K, Culbertson M, Bradke F, Tessier-Lavigne M, Tuszynski MH (2008) Netrin-1 is a novel myelin-associated inhibitor to axon growth. J Neurosci 28:1099-1108.

Luo Y, Raible D, Raper JA (1993) Collapsin: a protein in brain that induces the collapse and paralysis of neuronal growth cones. Cell 75:217-227.

Magliozzi R, Columba-Cabezas S, Serafini B, Aloisi F (2004) Intracerebral expression of CXCL13 and BAFF is accompanied by formation of lymphoid follicle-like structures in the meninges of mice with relapsing experimental autoimmune encephalomyelitis. J Neuroimmunol 148:11-23.

McCallum SA, Bazan JF, Merchant M, Yin J, Pan B, de Sauvage FJ, Fairbrother WJ (2006) Structure of SAP18: a ubiquitin fold in histone deacetylase complex assembly. Biochemistry 45:11974-11982.

McGee AW, Strittmatter SM (2003) The Nogo-66 receptor: focusing myelin inhibition of axon regeneration. Trends Neurosci 26:193-198.

McKerracher L, David S (2004) Easing the brakes on spinal cord repair. Nat Med 10:1052-1053.

Novak AJ, Bram RJ, Kay NE, Jelinek DF (2002) Aberrant expression of B-lymphocyte stimulator by B chronic lymphocytic leukemia cells: a mechanism for survival. Blood 100:2973-2979.

Yan M, Marsters SA, Grewal IS, Wang H, Ashkenazi A, Dixit VM (2000) Identification of a receptor for BLyS demonstrates a crucial role in humoral immunity. Nat Immunol 1:37-41.

Zheng B, Atwal J, Ho C, Case L, He XL, Garcia KC, Steward O, TessierLavigne M (2005) Genetic deletion of the Nogo receptor does not reduce neurite inhibition in vitro or promote corticospinal tract regeneration in vivo. Proc Natl Acad Sci U S A 102:1205-1210. 